\title{
Bird schistosomes of wildfowl in the Czech Republic and Poland
}

\author{
Jitka Rudolfová ${ }^{1}$, D.T.J. Littlewood ${ }^{2}$, Jiljí Sitko $^{3}$ and Petr Horák ${ }^{1}$ \\ ${ }^{1}$ Charles University in Prague, Faculty of Science, Department of Parasitology, Viničná 7, 12844 Prague 2, Czech Republic; \\ ${ }^{2}$ The Natural History Museum, Department of Zoology, Cromwell Road, London SW7 5BD, UK; \\ ${ }^{3}$ Komenský Museum, Horní nám. 7, 75011 Přerov 2, Czech Republic
}

Key words: schistosomes, wildfowl, Trichobilharzia, Bilharziella

\begin{abstract}
In 2005, we dissected 102 wildfowl from the Czech Republic and 73 wildfowl from Poland including representatives of Anseriformes, Gruiformes and Gaviiformes. Schistosome infection was found in a total of $21(29 \%)$ and 23 (23\%) birds from Poland and the Czech Republic, respectively. All infected birds belonged to the order Anseriformes. The prevalences of nasal and visceral species were, respectively, $22 \%$ and $16 \%$ in Poland and $6 \%$ and $19 \%$ in the Czech Republic. Four species of schistosomes were found: Bilharziella polonica Kowalewski, 1895, Trichobilharzia regenti Horák, Kolářová et Dvořák, 1998, T. szidati Neuhaus, 1952, and an undetermined schistosome from the intestinal wall of Anas penelope L. The finding of T. szidati represents the first record of the parasite from natural final host since the species description.
\end{abstract}

Bird schistosomes have become intensively studied parasites. This is mainly due to the fact that some bird schistosome species are causative agents of human cercarial dermatitis (swimmer's itch) - a hypersensitive skin reaction produced by cercarial penetration of the skin (Cort 1928). Occurrence of this disease might adversely affect tourism in some important recreational areas with associated economic losses. Therefore, various methods of controlling swimmer's itch are used in affected areas (Blankespoor and Reimink 1991). Besides evoking skin hypersensitivity, experiments have shown that bird schistosomes can migrate and partially develop also in other organs of their non-specific mammalian hosts, causing more serious health problems. Larvae of various visceral bird schistosomes have been found in the lungs of experimental rodents and monkeys (Horák et al. 2002), and leg paralysis has been observed in mice infected with the neurotropic species Trichobilharzia regenti Horák, Kolářová et Dvořák, 1998 (Horák et al. 1999). Thus, as a consequence of these experiments, it is conceivable that bird schistosomes might also be responsible for some pulmonary or nervous symptoms in humans.

In the wild, little is known about prevalence and impact of schistosome infections in wildfowl, or about the natural final host spectrum. This is likely a result of the minute dimensions of most bird schistosome species, making such studies very difficult. Finding these parasites usually requires skilled helminthological examination. Recent studies showed that bird schistosomes are quite frequent in anatid birds of Western and Northern Europe (Simon-Martin and Simon-Vicente 1999, Skírnisson and Kolářová 2005, Bayssade-Dufour et al. 2006, Kolářová et al. 2006).

In Central Europe, the nasal species $T$. regenti was shown to parasitize anatid birds frequently (Rudolfová et al. 2002) and, in addition, a visceral species Trichobilharzia sp. was found in the pied-wagtail (Motacilla alba L.) (Rudolfová et al. 2006). Earlier studies of wildfowl indicate, however, that the species spectrum of bird schistosomes in Central Europe (Czech Republic, Slovakia, Poland, Hungary) might be broader, as shown from the reports of Trichobilharzia kowalewskii (Ejsmont, 1929) McMullen et Beaver, 1945 (Ejsmont 1929), T. filiformis (Szidat, 1938) McMullen et Beaver, 1945 (Rudolfová, unpubl.), Gigantobilharzia mo-nocotylea Szidat, 1930 (Sulgostowska 1960), G. acotylea Odhner, 1910 (Macko 1964, Sitko 1968), Bilharziella polonica Kowalewski, 1895 (Khalifa 1972) and Dendritobilharzia pulverulenta (Braun, 1901) Skrjabin, 1924 (Khalifa 1976). In addition, several other species were found exclusively in their snail hosts and only their experimental final hosts are known (Trichobilharzia szidati Neuhaus, 1952 and T. franki Müller et Kimmig, 1994 reported by Rudolfová et al. 2005, and Gigantobilharzia mazuriana Khalifa, 1974 reported by Khalifa 1974), or both natural and experimental final hosts remain unknown (various findings of bird schistosomes from lymnaeid, physid and planorbid snails, e.g. Našincová 1992).

In the past, isolates of bird schistosomes from different snail hosts were routinely determined as Trichobilharzia ocellata (La Valette, 1855), Brumpt, 1931. However, species of the genus Trichobilharzia usually have a narrow specificity towards their intermediate host (Blair and Islam 1983). In detail, "Cercaria ocellata" was originally described from the snail Lymnaea stagnalis L. (La Valette 1855) and, therefore, the isolates from other snails probably belong to different bird schistosomes. Based on molecular analysis, the Euro-

This paper was presented at the XI International Congress of Parasitology - ICOPA XI, held in Glasgow, UK, August 6-11, 2006. 
pean " $T$. ocellata" isolates from Lymnaea stagnalis were found to be identical with $T$. szidati (Rudolfová et al. 2005). Moreover, a historical analysis of the genus Trichobilharzia (Rudolfová et al. 2005) enables the name $T$. szidati to be used exclusively in the present study, whilst suppressing the name "T. ocellata" (species inquirenda in our view).

As indicated, schistosomes found as larvae in various freshwater snails should at least partially complete their life cycle under conditions present in Central Europe. Therefore, the aim of our present work was to perform an extensive examination of wildfowl from the Czech Republic and Poland for both nasal and visceral schistosomes and find out prevalence of schistosome infections. Identity of schistosomes was assessed by sequencing the ITS region of rDNA.

\section{MATERIALS AND METHODS}

During the year 2005, a total of 102 water birds from the Czech Republic and 73 birds from Poland were dissected. Birds from the Czech Republic (locality: Central Moravia, ponds in Tovačov and Záhlinice) belonged to 9 species from three orders: Anseriformes - Anas clypeata L., A. crecca L., A. platyrhynchos L., A. querquedula L., A. strepera L., Aythya ferina (L.), A. fuligula (L.); Gruiformes - Fulica atra L.; Gaviiformes - Gavia arctica L. Birds from Poland (locality: Northern Poland, Gdansk) belonged to 13 species from three orders: Anseriformes - A. clypeata, A. crecca, A. penelope L., A. platyrhynchos, A. strepera, Aythya ferina, A. fuligula, Clangula hyemalis (L.), Melanita fusca L.; Gruiformes - F. atra; Charadriiformes - Alca torda L., Larus argentatus Pontopp., Uria algae Pontopp. Birds were found dead or shot either during hunts or through collecting under relevant permits. Birds for dissection were generally fresh; only sea birds were frozen. Nasal tissue, liver, intestinal veins and intestinal wall were examined for schistosomes. If eggs, miracidia or adults of these parasites were found, they were fixed in $96 \%$ ethanol for molecular analysis. Sequencing of the ITS (internal transcribed spacer) region of rDNA (including part of $18 \mathrm{~S}$ rRNA gene, ITS1, 5.8S rRNA gene, ITS2 and part of 28S rRNA gene) was used for evaluation of their identity.

Before DNA extraction, all ethanol from samples was removed by pipetting and speed-vac. Genomic DNA was iso- lated using Aqua Pure Genomic DNA Isolation Kit (Bio-Rad) according to manufacturer's instructions. Polymerase chain reactions were performed in reaction volume of $25 \mu 1$. Specific primers its4Trem (5'-TCCTCCGCTTATTGATATGC-3'), complementary to the conserved region at 5 '-end of the $28 \mathrm{~S}$ rRNA gene, and its5Trem (5'-GGAAGTAAAAGTCGTAAC AAGG-3'), complementary to the conserved region at the 3'end of the 18S rRNA gene, were used for amplification of the whole ITS region. The reaction mixture contained $2.5 \mu 1$ of the DNA template, $0.2 \mu \mathrm{M}$ of each primer (Generi Biotech), $1 \times$ Taq polymerase buffer (Bioline), $2 \mathrm{mM} \mathrm{MgCl}_{2}$ (Bioline), 200 $\mu \mathrm{M}$ dNTP (Bioline) and 0.65 unit of Taq polymerase (Bioline). The reaction temperature profile included the initial denaturation step at $95^{\circ} \mathrm{C}$ for $60 \mathrm{sec}$ followed by 30 cycles of denaturation at $95^{\circ} \mathrm{C}$ for $50 \mathrm{sec}$, annealing at $50^{\circ} \mathrm{C}$ for $40 \mathrm{sec}$ and extension at $72^{\circ} \mathrm{C}$ for $110 \mathrm{sec}$, with a final extension step at $72^{\circ} \mathrm{C}$ for $10 \mathrm{~min}$ (Brant S.V., U.N.M., Albuquerque, USA; pers. comm.). Polymerase chain reactions were carried out in MyCycler thermal cycler (Bio-Rad).

The PCR products were purified from the PCR mixture using SureClean (Bioline) or from agarose gel using MinElute Gel Extraction Kit (Qiagen). Purified PCR products were sequenced directly. In most samples it was necessary to clone the purified PCR products as well. TOPO TA Cloning Kit for Sequencing with chemically competent TOP 10 Escherichia coli cells (Invitrogen) was used. Plasmid DNA was prepared using QIAquick Spin Miniprep Kit (Qiagen).

Sequencing reactions were carried out using BigDye Terminator v3.1 Cycle Sequencing Kit (Applera) according to the manufacturer's protocol. Two clones from two independent amplification reactions of each DNA isolate were sequenced. In case of disagreement between the two clones, a third clone from an independent amplification reaction was sequenced. Sequencing primers M13F and M13R (Sigma) annealing to plasmid sites, and specific primers (Generi Biotech) annealing to the DNA insert - its4Trem, its5Trem, its2Trem (5'GCTGCACTCTTCATCGACGC-3'), its3Trem (5'-GCGTCG ATGAAGAGTGCAGC-3'), ITS6-F (5'-CTGTTGCTAAAC TGAAAC-3') and ITS6-R (5'-GGATGATTGACTGCG-3') were used for sequencing reactions. The products of sequencing reactions were analyzed on an ABI PRISM 3100-Avant automated sequencer (Applied Biosystems). The sequences were deposited in GenBank under the accession numbers EF094530-EF094541.

Table 1. Isolates of bird schistosomes used for phylogenetic analysis. ND - not determined.

\begin{tabular}{llllll}
\hline Isolate & Determination & Stage & Location & Host & Locality \\
\hline P117 & Trichobilharzia sp. 1 & eggs & nasal tissue & Aythya fuligula & Gdansk, PL \\
P13 & ND & eggs & intestinal wall & Anas crecca & Gdansk, PL \\
P17 & ND & eggs & intestinal wall & A. penelope & Gdansk, PL \\
P110 & ND & eggs & intestinal wall & A. penelope & Gdansk, PL \\
P114 & Trichobilharzia sp. 1 & eggs & nasal tissue & A. clypeata & Gdansk, PL \\
P120 & Trichobilharzia sp. 1 & eggs & nasal tissue & A. platyrhynchos & Gdansk, PL \\
P121 & ND & eggs & intestinal wall & A. platyrhynchos & Gdansk, PL \\
P127 & Trichobilharzia sp. 1 & eggs, adults & nasal tissue & A. platyrhynchos & Gdansk, PL \\
Cz11 & Trichobilharzia sp. 2 & adult & liver & A.platyrhynchos & Tovačov, CZ \\
Cz31 & Trichobilharzia sp. 1 & eggs, miracidia & nasal tissue & A. platyrhynchos & Tovačov, CZ \\
Cz39 & Bilharziella polonica & adult & intestinal wall & A. platyrhynchos & Tovačov, CZ \\
Cz79 & Trichobilharzia sp. 1 & eggs, miracidia & nasal tissue & A. clypeata & Tovačov, CZ \\
\hline
\end{tabular}


Table 2. GenBank sequences of bird schistosomes used for phylogenetic analysis.

\begin{tabular}{ll}
\hline Isolate & Accession number \\
\hline Gigantobilharzia sp. & AY713963 \\
Dendritobilharzia pulverulenta & AY713962 \\
Allobilharzia visceralis & DQ067561 \\
Trichobilharzia regenti & AF263829 \\
Trichobilharzia franki & AF356845 \\
T. franki $(\mathrm{Ra} 1)$ & AY713969 \\
T. franki $(\mathrm{Ra} 2)$ & AY713964 \\
T. franki $(\mathrm{Ra} 3)$ & AY713966 \\
T. franki $(\mathrm{Ls} 1)$ & AY713973 \\
T. szidati $(\mathrm{ToA})$ & AY713970 \\
T. szidati $($ ToE) & AY713971 \\
T. szidati $(\mathrm{Tsz})$ & AY713972 \\
T. szidati & AF263828 \\
T. szidati $(\mathrm{Ls} 2)$ & AY713961 \\
T. szidati $(\mathrm{Ls3})$ & AY713968 \\
T. szidati $(\mathrm{Ls4})$ & AY713965 \\
T. szidati $(\mathrm{Ls5})$ & AY713967 \\
\hline
\end{tabular}

For phylogenetic analysis the new sequences (Table 1) and the sequences of $T$. regenti, T. franki, T. szidati, Dendritobilharzia pulverulenta, Gigantobilharzia sp. and Allobilharzia visceralis downloaded from the GenBank database (accession numbers AF263828, AF263829, AF356845, AY713961-73, DQ067561; Table 2) were used. Sequences of Schistosoma rodhaini and S. mansoni (accession numbers AF531312, AF531314) served as outgroups. Sequences were aligned in Clustal_X 1.83 and the alignment was manually refined in Bioedit 5.0.9. The region containing part of ITS1, whole 5.8S rDNA, ITS2 and part of 28S rDNA (896 positions) was used for tree construction.

The phylogenetic analyses using maximum parsimony were performed in PAUP* v.4.0 (Swofford 2002). The tree space was searched by 10 replicates of heuristic search, with starting tree constructed by random taxa addition and TBR swapping. Maximum likelihood analysis was done in program Phyml (Guindon and Gascuel 2003) using the GTR $+\mathrm{I}+\Gamma$ model with parameters estimated by the software. Node support was assessed by bootstrapping (100 replicates for maximum likelihood, 1,000 replicates for maximum parsimony). Phylogenetic analysis using Bayesian inference was performed with MrBayes 3.1.1 (Huelsenbeck and Ronquist 2001). Four simultaneous Markov Monte Carlo chains (temperature 0.2 ) were run for $2,000,000$ generations under covarion GTR $+\mathrm{I}+\Gamma$ substitution model and sampled every 100 generations. The first 5,000 trees were discarded as the 'burnin'.

\section{RESULTS}

Adults and/or eggs of bird schistosomes were found in $21(29 \%)$ out of 73 birds from Poland (Table 3). Nasal schistosomes were discovered in $16(22 \%)$ birds, visceral schistosomes in $12(16 \%)$ birds. Seven $(10 \%)$ specimens were infected by both nasal and visceral schistosomes. Infected birds belonged to the order Anseriformes, birds from other orders were not positive for schistosomes. All samples of nasal schistosomes had the same morphology; i.e. spindle-shaped eggs and filiform adults with two suckers and short gynaecophoric canal.
Based on their morphology, they were determined as Trichobilharzia sp. 1. Further determination was not possible, as only fragments of adults with no speciesspecific characteristics were isolated from the nasal tissue. Three visceral schistosomes were distinguished based on morphology: (1) Adults with flattened body, oral and ventral sucker and short gynaecophoric canal, isolated from intestinal veins of two birds. They were determined as Bilharziella polonica. (2) Crescentic eggs from the wall of the large intestine of 7 birds. (3) Spindle-shaped eggs from the wall of the large intestine of 4 birds. Species determination by means of egg morphology was not possible, because different species can have similar shape and size of eggs.

In the Czech Republic, schistosomes were found in $23(23 \%)$ out of 102 birds (Table 4). Six (6\%) birds were infected by nasal species and 19 (19\%) birds by visceral ones. Both nasal and visceral schistosomes were found in $2(2 \%)$ birds. Only anseriform birds were infected with schistosomes. All samples of nasal schistosomes had the same morphology - spindle-shaped eggs and filiform adults with two suckers and short gynaecophoric canal. They appeared to be morphologically identical with the species found in birds from Poland and, therefore, they were determined as Trichobilharzia sp. 1. Visceral schistosomes belonged to several morphological types or species: (1) Bilharziella polonica was found in 14 birds. Thirteen of them harboured adults in intestinal veins; in one specimen typical eggs (oval with spine and long protuberance) were found in intestinal wall. (2) Spindle-shaped eggs in the wall of the large intestine were found in three birds. Their determination based on morphology was not possible. (3) Filiform adults with oral and ventral sucker and short gynaecophoric canal were found in liver of two birds. They were determined as Trichobilharzia sp. 2.

No pathological changes of inner organs were observed in birds infected with schistosomes. Intensity of infection in birds was low: less than 10 eggs and 1-3 adults were found in infected individuals. As an exception, one $A$. clypeata harboured 5 adults and tens of eggs and miracidia of a nasal schistosome. In one $A$. platyrhynchos, 13 adults of $B$. polonica were found.

The phylogenetic analysis was based only upon the non-repetitive parts of ITS1, 5.8S rDNA, ITS2 and 28S rDNA, because sequence diversity and tandem repeats within the long repeat region in the ITS1 prevented use of this region. The phylogenetic tree based on the sequences of our isolates and the sequences deposited in GenBank is given in Fig. 1. The tree was rooted using Schistosoma rodhaini and $S$. mansoni sequences.

Our isolate $\mathrm{Cz} 39$ morphologically determined as Bilharziella forms a separate branch basal to all other bird schistosome isolates. These constitute two clades: the first clade is formed by D. pulverulenta and Gigantobilharzia sp. (bootstrap support 96-99\%, posterior prob- 
Table 3. Results of wildfowl examination for schistosomes (Gdansk area, Poland).

\begin{tabular}{lcccc}
\hline \multicolumn{1}{c}{ Species } & Examined & $\begin{array}{c}\text { Infected with } \\
\text { nasal schistosomes }\end{array}$ & $\begin{array}{c}\text { Infected with } \\
\text { visceral schistosomes }\end{array}$ & $\begin{array}{c}\text { Infected } \\
\text { in total }\end{array}$ \\
\hline Anas clypeata & 6 & 4 & 4 & 5 \\
A. crecca & 6 & 0 & 1 & 1 \\
A. penelope & 6 & 0 & 2 & 2 \\
A. platyrhynchos & 12 & 10 & 4 & 10 \\
A. strepera & 2 & 0 & 1 & 1 \\
Aythya ferina & 2 & 0 & 0 & 0 \\
A. fuligula & 3 & 2 & 0 & 2 \\
Clangula hyemalis & 12 & 0 & 0 & 0 \\
Melanita fusca & 2 & 0 & 0 & 0 \\
Anseriformes in total & 51 & $16(31 \%)$ & 0 & $21 \%)$ \\
Fulica atra & 10 & 0 & 0 & 0 \\
Alca torda & 4 & 0 & 0 & 0 \\
Uria algae & 7 & 0 & 0 & 0 \\
Larus argentatus & 1 & 0 & $12(16 \%)$ & 0 \\
\hline Total & 73 & $16(22 \%)$ & & $21(29 \%)$ \\
\hline
\end{tabular}

Table 4. Results of wildfowl examination for schistosomes (Záhlinice and Tovačov, Czech Republic).

\begin{tabular}{lcccc}
\hline \multicolumn{1}{c}{ Species } & Examined & $\begin{array}{c}\text { Infected with } \\
\text { nasal schistosomes }\end{array}$ & $\begin{array}{c}\text { Infected with } \\
\text { visceral schistosomes }\end{array}$ & $\begin{array}{c}\text { Infected } \\
\text { in total }\end{array}$ \\
\hline Anas clypeata & 2 & 1 & 1 & 1 \\
A. crecca & 8 & 0 & 4 & 4 \\
A. platyrhynchos & 66 & 3 & 11 & 14 \\
A. querquedula & 5 & 0 & 2 & 2 \\
A. strepera & 1 & 0 & 0 & 0 \\
Aythya ferina & 12 & 1 & 0 & 1 \\
A. fuligula & 5 & 1 & 1 & 1 \\
Anseriformes in total & 99 & $6(6 \%)$ & 0 & $23(23 \%)$ \\
Fulica atra & 2 & 0 & 0 & 0 \\
Gavia arctica & 1 & 0 & $19(19 \%)$ & 0 \\
\hline Total & 102 & $6(6 \%)$ & & $23(23 \%)$ \\
\hline
\end{tabular}

ability 1.00), the second clade contains sequences of Allobilharzia visceralis and Trichobilharzia spp. from database and our isolates from wildfowl (bootstrap support $53-57 \%$, posterior probability 0.61 ).

The Trichobilharzia clade is divided into several branches: (1) A. visceralis, (2) isolates P17 and Pl10, (3) T. regenti and isolates $\mathrm{P} 114, \mathrm{P} 117, \mathrm{P} 120, \mathrm{P} 127, \mathrm{Cz} 31$ and Cz79, (4) T. franki, and (5) T. szidati" "T. ocellata" and isolates P13, P121 and Cz11. The described topology has nodal support 93-94\%, posterior probability 1.00 .

\section{DISCUSSION}

Our results indicate that schistosomes are frequent parasites of anatid birds. This corresponds to our previous studies (Rudolfová et al. 2002, Bayssade-Dufour et al. 2006) which, however, focused only on selected bird schistosomes (nasal Trichobilharzia, Bilharziella and Dendritobilharzia). The present study is more complex, because it centres on a broader spectrum of birds and their schistosome parasites.

Four schistosome species were found in our study. Their identification was based on morphology and/or sequencing of the ITS region. Bilharziella polonica possesses typical morphological characters guaranteeing correct identification. Phylogenetic analysis based on the ITS region confirmed the conclusions of Lockyer et al. (2003): Bilharziella is basal to the clade Dendritobil- harzia, Gigantobilharzia, Allobilharzia and Trichobilharzia and, therefore, the subfamily Bilharziellinae (including also the genus Trichobilharzia at present) is not monophyletic and should be rejected. Based on sequencing, all findings of nasal schistosomes from wildfowl from the Czech Republic and Poland (Cz31, Cz79, P114, P117, P120 and P127) were demonstrated to belong to the same species, T. regenti; this confirmed our previous results (Rudolfová et al. 2002). Several samples of visceral schistosomes were found to belong to T. szidati: crescentic eggs from the intestinal wall of A. platyrhynchos from Poland (P13, $\mathrm{P} 121)$ and an adult from the liver of $A$. platyrhynchos from the Czech Republic (Cz11). Crescentic eggs were found also in $A$. clypeata from Poland. Although the DNA extraction from these samples failed, based on the same morphology, location and locality, we propose they belong to $T$. szidati as well. The location of $T$. szidati adults in liver is unusual, as these worms live in the intestinal wall, but it can be explained by worm migration to the site of final localisation. T. szidati was frequently found in its cercarial stage, and its life cycle was completed experimentally; A. platyrhynchos proved to be a suitable final host under laboratory conditions. Neuhaus (1952) proposed A. platyrhynchos (syn. A. boscas) and Aythya ferina as natural final hosts for this species, as they occurred in the same locality as the infected snails, but 


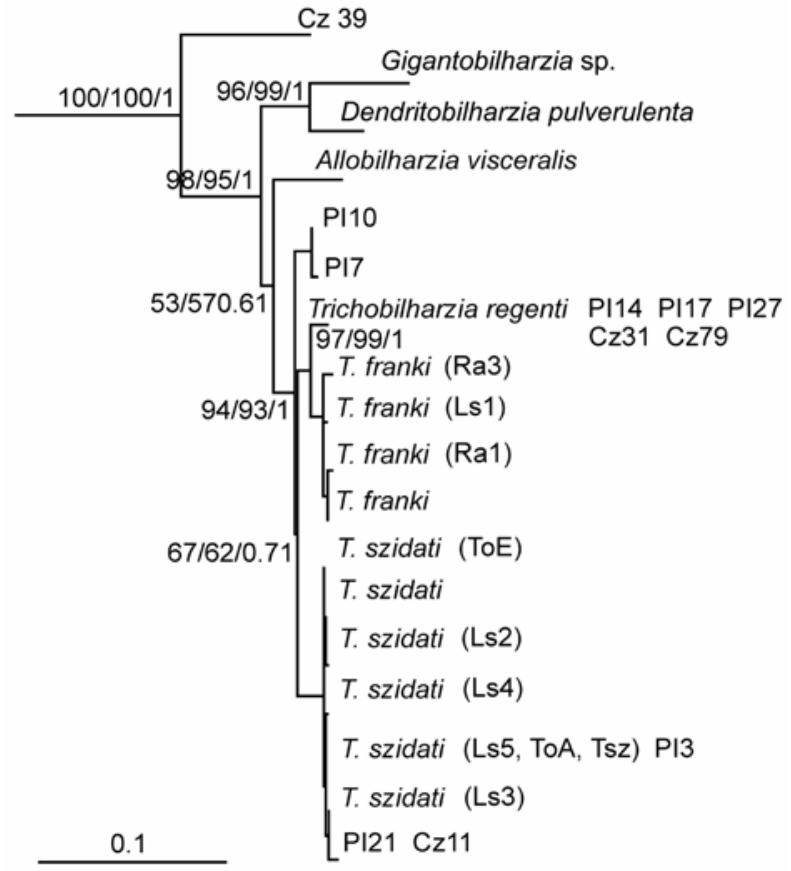

Fig. 1. The phylogenetic tree of bird schistosome isolates based on the partial sequences of the ITS region. The sequences of Schistosoma rodhaini and S. mansoni were used as outgroup. To save space, Schistosoma sequences were removed and their position is indicated by a line. The tree was constructed using the maximum likelihood method in Phyml (GTR $+\mathrm{I}+\Gamma$ model of substitution). The node support is given in maximum parsimony bootstraps, maximum likelihood bootstraps and Bayesian posterior probability.

he did not perform dissections of wildfowl. Indeed, in subsequent studies T. szidati was not reported from any wildfowl either. Based on sequencing of the ITS region, $T$. szidati was found to be identical with " $T$. ocellata" isolates from L. stagnalis from laboratories in Germany and in the Netherlands (Rudolfová et al. 2005). However, it is not possible to conclude that $T$. ocellata is identical with $T$. szidati in general, as many different isolates and species were assigned to " $T$. ocellata" in the past. In Europe, "T. ocellata" was found in the liver of anatid birds in Russia (Bykhovskaya-Pavlovskaya and Ryzhikov 1958), but it differs from T. szidati in the position of caecal reunion in males and in the shape of eggs. Therefore, our finding of T. szidati represents the first report of this species from a natural final host. Species determination of spindle-shaped eggs from the intestinal wall of $A$. penelope from Poland (P17, P110) was not possible. This type of eggs is common within the genus Trichobilharzia, but it occurs also in Dendritobilharzia. The position of the undetermined species (isolates Pl7 and Pl10) in the phylogenetic tree is sister taxon to Trichobilharzia isolates and, without morphology, it is not possible to conclude whether they belong to Trichobilharzia or represent another genus of bird schistosomes. In Europe, T. kowalewskii and T. salman- ticensis have this type and location of eggs (Bykhovskaya-Pavlovskaya and Ryzhikov 1958, SimonMartin and Simon-Vicente 1999). However, A. penelope migrates to Africa and South Asia (Hudec 1994), so the eggs found could belong to one of the species described from these regions as well. Further dissections providing specimens for morphological examinations and more database sequences for comparison should elucidate the problem.

Despite the frequent occurrence of bird schistosomes in wildfowl, their pathogenicity remains questionable. Graczyk et al. (1993) and Pence and Rhodes (1982) reported fatal schistosome infections in anatid birds caused by Trichobilharzia physellae in the USA. In Europe, Kolářová et al. (2006) observed endophlebitis, inflammation of intestinal wall and also pathologies in the liver and lungs of whooper swans (Cygnus cygnus) infected with $A$. visceralis. Infected individuals were emaciated. T. filiformis was found to cause obliterative endophlebitis that might contribute to emaciation and death of infected mute swans (Cygnus olor; van Bolhuis et al. 2004). Palmer and Ossent (1984) found Trichobilharzia sp. in nasal tissue of C. olor treated in an animal clinic; some of the birds displayed leg weakness of unknown origin. Horák et al. (1999) performed experimental infections of domestic ducklings (A. platyrhynchos f. dom.) with the neurotropic nasal species $T$. regenti and observed leg paralysis and orientation and balance disorders; high infection dose of cercariae could lead to death. In contrast to the above studies, we did not observe any macroscopical changes in nasal tissue, intestine or liver of infected birds. They were not lean, with considerable amount of fat found in some birds. There are at least two explanations for this fact: (1) birds usually meet lower infection doses under natural conditions and the intensity of infection in most birds studied was very low; (2) pathogenicity of schistosome infection for birds is species-specific and, therefore, only some bird schistosomes cause severe diseases.

In conclusion, schistosomes seem to be relatively frequent parasites of anatid birds in Central Europe. Four species of schistosomes were found, with the first report of $T$. szidati from a natural final host. One of the species found could not be determined due to the lack of morphological characters and insufficient number of database sequences for comparison. Pathogenicity of schistosome infections for wildfowl remains questionable, because it probably depends on schistosome species and intensity of infection, but also other unknown factors might be important. Relatively high prevalence of schistosome infections in wildfowl might influence occurrence of cercarial dermatitis in humans in both nesting and wintering areas.

There remains a need for molecular diagnostic markers to be determined for schistosomes of wildfowl to aid in taxonomy, systematics and much needed epidemiological studies. 
Acknowledgements. We thank Gerard Kanarek for help with getting birds in Poland. This project was supported by the Ministry of Education, Youth and Sports of the Czech Republic (Grants No. MSM0021620828 and No. MSM LC06009), by Charles University Grant Agency (Grant No. 166/2005/B$\mathrm{BIO} / \mathrm{PrF}$ ) and by the Czech Science Foundation (Grant No. IAA 6022404).

\section{REFERENCES}

BAyssade-Dufour C., Jouet D., Rudolfová J., HorÁK P., FERTÉ H. 2006: Seasonal morphological variations in bird schistosomes. Parasite 13: 205-214.

BLAIR D., ISLAM K.S. 1983: The life cycle and morphology of Trichobilharzia australis $\mathrm{n}$. sp. (Digenea: Schistosomatidae) from the nasal blood vessels of the black duck (Anas superciliosa) in Australia, with a review of the genus Trichobilharzia. Syst. Parasitol. 5: 89-117.

BLANKESPOOR H.D., REIMINK R.L. 1991: The control of swimmer's itch in Michigan: past, present and future. Mich. Academician 24: 7-23.

BYKHOVSKAYA-PAVLOVSKAYA I.E., RYZHIKOV K.M. 1958: [Schistosomes (Schistosomatidae Looss, 1899) of anseriform birds of Yakutiya]. Parazitol. Sb. 18: 283-294. (In Russian.)

CORT W.W. 1928: Schistosome dermatitis in the United States (Michigan). J. Am. Med. Assoc. 90: 1027-1029.

EJSMONT M.L. 1929: Über zwei Schistosomatidengattungen der Vögel. Bull. Acad. Pol. Sci. Lett., Sci. Nat., 2: 389-403.

GRACZYK T.K., SHIFF C.J., SLADEN J.L., CRANFIELDT M. 1993: Attempts to control avian blood flukes in a national wildfowl refuge and in a captive system. In: F.B. Andrews (Ed.), Proceedings of the 24th Annual Conference of the International Association of Aquatic Animal Medicine. Chicago University Press, Chicago, pp. 79-83.

GUINDON S., GASCUEL O. 2003: A simple, fast, and accurate algorithm to estimate large phylogenies by maximum likelihood. Syst. Biol. 52: 696-704.

HorÁK P., DVOŘÁK J., KOLÁŘOVÁ L., TREFIL L. 1999: Trichobilharzia regenti, a pathogen of the avian and mammalian central nervous systems. Parasitology 119: 577-581.

HorÁK P., KolÁŘOVÁ L., ADEMA C.M. 2002: Biology of the schistosome genus Trichobilharzia. Adv. Parasitol. 52: 155233.

HUDEC K. (Ed.) 1994: [Fauna of the Czech Republic and Slovak Republic. Birds. Part 1.] Academia, Prague, pp. 463-468. (In Czech.)

HUELSENBECK J.P., RONQUIST F. 2001: MrBayes: Bayesian inference of phylogenetic trees. Bioinformatics 17: 754-755.

KHALIFA R. 1972: Studies on Schistosomatidae Looss, 1899 (Trematoda) of aquatic birds of Poland. I. On the life cycle of Bilharziella polonica Kowalewski, 1895, with a discussion of the subfamily Bilharziellinae Price, 1929. Acta Parasitol. 20: 343-365.

KHALIFA R. 1974: Studies on Schistosomatidae Looss, 1899 (Trematoda) of aquatic birds of Poland. II. Gigantobilharzia mazuriana sp. n., with a discussion of the subfamily Gigantobilharziinae Mehra, 1940. Acta Parasitol. 22: 265-284.

KhALIFA R. 1976: Studies on Schistosomatidae Looss, 1899 (Trematoda) of aquatic birds of Poland. III. Notes on the morphology and life cycle of Dendritobilharzia pulverulenta (Braun, 1901). Acta Parasitol. 24: 1-9.

KolÁŘOVÁ L., RUdOlFOVÁ J., HAMPL V., SKÍRNISSON K. 2006 Allobilharzia visceralis gen. nov., sp. nov. (SchistosomatidaeTrematoda) from Cygnus cygnus (L.) (Anatidae). Parasitol. Int. 55: 179-186.
LA VAlette DE ST. GeORGE A. 1855: Symbolae ad trematodum evolutionis historiam. Dissertation, Berolius.

LOCKYER A.E., OLSON P.D., ØSTERGAARD P., ROLLINSON D., JOHNSTON D.A., ATTWOOD S.W., SOUTHGATE V.R., HoRÁK P., SNYder S.D., Le T.H., Agatsuma T., MCMANUS D.P., CARMiChaEl A.C., NAEM S., LitTLEWOOD D.T.J. 2003: The phylogeny of the Schistosomatidae based on three genes with emphasis on the interrelationships of Schistosoma Weinland, 1858. Parasitology 126: 203-224.

MACKO J.K. 1964: Beitrag zur Fauna der Trematoden von Lariden aus den Zugwegen der Slowakei (ČSSR). Helminthologia 5: 85-106.

NAŠINCOVÁ V. 1992: [Developmental stages of trematodes in our water snails and life cycles of selected species from the families Omphalometridae and Echinostomatidae.] Ph.D. Thesis, University of South Bohemia, České Budějovice, Czech Republic, 268 pp. (In Czech.)

NeuHAus W. 1952: Biologie und Entwicklung von Trichobilharzia szidati $\mathrm{n}$. sp. (Trematoda, Schistosomatidae), einem Erreger von Dermatitis beim Menschen. Z. Parasitenkd. 15: 203266.

PALMER D., OSSENT P. 1984: Nasal schistosomiasis in mute swans in Switzerland. Rev. Suisse Zool. 91: 709-715.

PENCE D.B., RHODES M.J. 1982: Trichobilharzia physellae (Digenea: Schistosomatidae) from endemic waterfowl on the High Plains of Texas. J. Wildl. Dis. 18: 69-74.

Rudolfová J., HAMPl V., BAysSAde-Dufour C., LOCKYeR A.E., LITTLEWOOD D.T.J., HORÁK P. 2005: Validity reassessment of Trichobilharzia species using Lymnaea stagnalis as the intermediate host. Parasitol. Res. 95: 79-89.

RudolfovÁ J., SitKo J., HORÁK P. 2002: Nasal schistosomes in wildfowl in the Czech Republic. Parasitol. Res. 88: 10931095.

RUdOlfovÁ J., SitKo J., HORÁK P. 2006: Unusual finding of Trichobilharzia sp. in Motacilla alba in the Czech Republic. J. Helminthol. 80: 83-85.

Simon-Martin F., SimOn-Vicente F. 1999: The life cycle of Trichobilharzia salmanticensis $\mathrm{n}$. sp. (Digenea: Schistosomatidae), related to case of human dermatitis. Res. Rev. Parasitol. 59: 13-18.

SITKO J. 1968: Trematodes of birds of the family Laridae in Czechoslovakia. Acta Soc. Zool. Bohemoslov. 32: 275-292.

SKÍRNISSON K., KOLÁR̆OVÁ L. 2005: Swimmer's itch in Landmannalaugar, Iceland. Laeknabladid 91: 729-736. (In Icelandic.)

SULGOSTOWSKA T. 1960: Extra-intestinal trematodes in birds of the mesotrophic lakes: Goldapiwo and Mamry Polnocne. Acta Parasitol. 8: 471-492.

SWOFFORD D.L. 2002: PAUP*. Phylogenetic analysis using parsimony* and other methods. Sinauer, Sunderland, Mass.

VAN BOLHUIS G.H., RIJKS J.M., DORRESTEIN G.M., RUDOLFOVÁ J., VAN DIJK N., KUIKEN T. 2004: Obliterative endophlebitis in mute swans (Cygnus olor) caused by Trichobilharzia sp. (Digenea: Schistosomatidae) infection. Vet. Pathol. 41: 658665 . 